NBER WORKING PAPER SERIES

\title{
FOUR FACTS CONCERNING COMPETITION IN U.S. GENERIC PRESCRIPTION DRUG MARKETS
}

\author{
Rena M. Conti \\ Ernst R. Berndt \\ Working Paper 26194 \\ http://www.nber.org/papers/w26194 \\ NATIONAL BUREAU OF ECONOMIC RESEARCH \\ 1050 Massachusetts Avenue \\ Cambridge, MA 02138 \\ August 2019
}

Research support from the National Institutes of Health, Grant R01AG043560 (Berndt), and from the American Cancer Society and the Commonwealth Fund (Conti) is gratefully acknowledged. Much of the research reported here took place when Ms. Conti was Associate Professor at the University of Chicago. Mr. Berndt and Ms. Conti acknowledge research assistance from Steven J. Murphy and Hyun Moh (John) Shin. Any opinions and findings expressed here are those of the authors, and are not necessarily those of the institutions with whom they are affiliated, the research sponsors, the data vendor, or the National Bureau of Economic Research.

NBER working papers are circulated for discussion and comment purposes. They have not been peer-reviewed or been subject to the review by the NBER Board of Directors that accompanies official NBER publications.

(C) 2019 by Rena M. Conti and Ernst R. Berndt. All rights reserved. Short sections of text, not to exceed two paragraphs, may be quoted without explicit permission provided that full credit, including $(\odot$ notice, is given to the source. 
Four Facts Concerning Competition in U.S. Generic Prescription Drug Markets

Rena M. Conti and Ernst R. Berndt

NBER Working Paper No. 26194

August 2019

JEL No. I10,L10,L65

\begin{abstract}
$\underline{\text { ABSTRACT }}$
We establish four facts concerning competition among U.S. generic drug suppliers, using IQVIA's National Sales Perspective ${ }^{\mathrm{TM}} 2004 \mathrm{Q} 4$ - 2016Q3 data. We define a unique product market ("molform"), consisting of the combination of a molecule active ingredient and a route of administration formulation, aggregated over different dosages and strengths. We find: (i) supply exhibits substantial churning in entrants and exits; (ii) volume-weighted use concentrates in older generic molform cohorts; (iii) the extent of competition is greatest for the oldest molform cohorts and is smallest for the youngest molform cohorts. With a median of one competitor, the extent of competition in the youngest molform cohort is very limited; and (iv) supplier-molform annual revenues are typically small, are largest for relatively young drugs, but are heavily right skewed. These four facts provide an empirical platform on which to construct and empirically evaluate hypotheses regarding generic drug market structure, performance, and possible policy reforms.
\end{abstract}

\author{
Rena M. Conti \\ Boston University \\ Questrom School of Business \\ Department of Markets, Public Policy and Law \\ 595 Commonwealth Ave \\ Boston, MA 02215 \\ rconti@bu.edu \\ Ernst R. Berndt \\ MIT Sloan School of Management \\ 100 Main Street, E62-533 \\ Cambridge, MA 02142 \\ and NBER \\ eberndt@mit.edu
}




\section{INTRODUCTION}

off-patent 'generic' prescription drugs are a dominant component of the United States' medicinal armamentarium. In 2017, 90 percent of retail and mail order prescriptions in the United States (U.S.) were dispensed as generic drugs, and for those molecules for which a generic was available, the generic penetration rate was 97 percent (M. L. Aitken and Kleinrock 2018). Vigorous demand for generic products is buttressed by state laws and regulations requiring generic substitution when available, with limited exceptions.

The U.S. Food and Drug Administration (FDA) requires manufacturers to obtain approval to market a drug. On-patent 'branded' prescription drugs are marketed under the pioneer's FDA approved New Drug Application (NDA) that specifies its chemical composition, safety and efficacy in treating disease, and manufacturing procedures to comply with good manufacturing practices. Generic competition with a branded drug occurs after the branded product has lost patent or market exclusivity. FDA approval of a generic manufacturer's Abbreviated New Drug Application (ANDA) requires its sponsor to establish pharmaceutical and bioequivalence to the brand and compliance with good manufacturing practices; establishing safety and efficacy of the generic is not required. Thus, once generics are approved and certified by the FDA, competition among them, 
and between them and the brand, primarily involves price and assured availability and only minimally entails quality.

Observed differences between generic and brand pricing are a function of several factors. First, the development process of generic drugs is generally less costly than for the brand. Generic manufacturers also exploit technological developments and cost efficiency improvements since the original product was approved, enabling the generic manufacturer to attain lower variable production costs. Consequently, generics are frequently considered to be a commodity-type product with low marginal costs.

Second, like all consumer products, the number of unique competitors marketing a product affects its price. A substantial existing literature documents the marginal impact of additional numbers of generic entrants on generic price in the 24 months following initial loss of exclusivity (LOE) in largely orally formulated branded drugs (Berndt and Aitken 2011; Berndt and Newhouse 2012). Other research finds the extent of generic entry in the 24 months after LOE is in large part determined by pre-LOE sales volume (higher sales volume pre-LOE is associated with more entry post-LOE) and by product formulation (less entry among non-orally formulated drugs compared to oral formulations)(Conti and Berndt 2014). 
However, despite the very robust competitive entry and price competition exhibited by commonly used drugs in the 24 months post-LOE, not all post-LOE pioneer drugs face competition from generic competitors. Post-LOE entry by generic competitors may be frustrated or forestalled by the brand through various "pay for delay" agreements, or by successful line extension launches by the brand manufacturer (Drake, Starr, and McGuire 2015; McGuire et al. 2016; Drake and McGuire 2016). Various recent reports have raised questions regarding the adequacy of supplier competition in mature generic drug markets years after initial LOE. Government investigations have focused on factors associated with drug shortages involving largely old, injectible generic drugs (Conti and Berndt 2014; Collins and McCaskill 2016) and relatively rare, but highly visible, high prices and dramatic price increases (Collins and McCaskill 2016; Alpern, Stauffer, and Kesselheim 2014) involving generic drugs facing little if any market competition (Conti and Berndt 2014; Alpern, Stauffer, and Kesselheim 2014; Silverman 2014). Former Commissioner Gottlieb has interpreted the role of the FDA to include ensuring competition over generic drugs' lifecycle (U.S. Food and Drug Administration 2017). The Trump Administration's Blueprint to Lower Drug Prices suggested additional efforts the FDA, the Federal Trade Commission (FTC) and the Department of Justice (DOJ) might pursue to ensure and sustain robust generic 
drug competition over time (U.S. Department of Health and Human Services 2018).

Few studies have examined empirical levels and trends in the extent of generic drug supply. In this paper, we quantify competition in U.S. generic product markets using national sales prescription drug data. We are particularly interested in understanding the nature of mature competition among generic drug products in the later years following initial LOE to assess whether the intense competition observed immediately following LOE is sustained over time. Our goal is to provide an empirical platform on which to construct and empirically evaluate causal hypotheses and inform ongoing policy discussions (Dave et al. 2017) $\cdot 1$

\section{EMPIRICAL APPROACH}

Using national prescription drug sales and supplier data, we quantify and report statistics addressing the following questions: (i) How extensive is supplier churning (entry and exit) in branded and generic markets?; (ii) How old are the generic drugs commonly used by American consumers?; (iii) How many competitors does a typical generic product face and how does this vary by vintage?; (iv) How large are annual manufacturer revenues per generic product market, and how does 
this vary by vintage? And ( $v$ ) How do these relationships change over time and differ by generic product formulation?

Using commercially available data from IQVIA (formerly IMS Health and QuintilesIMS) National Sales Perspective ${ }^{\mathrm{TM}}$ (NSP) database, 2004Q4 - 2016Q3, we examine the universe of prescription drugs sold nationwide (Berndt, Conti, and Murphy 2017). NSP data derive from a projected audit of purchases from manufacturers or wholesalers to pharmacies, clinics, hospitals and other distribution outlets, covering 100 percent of the national unit volume in all major classes of trade and distribution channels. The data provides information on each prescription drug by specific chemical and brand name, formulation and name of the drug's labeler (FDA's terminology for the holder of the drug's NDA or ANDA) which we interpret here as the name of a given drug's manufacturer. ${ }^{2}$ The branded status of a drug is a variable assigned by NSP quarterly to account for loss of patent exclusivity and generic entry over time. NSP includes 'branded' drugs - those on some patent or other exclusivity and sold by only one manufacturer - and 'generic' or 'biosimilar' drugs - those with LOE and sold by one or more manufacturers. NSP distinguishes between 'oral', 'injectible' and 'other' product formulations. 'Other' products include drugs formulated as topicals and inhalants. 
We define product markets at the molecule-formulation level, "molform". This product market definition takes a molecule (e.g., atorvastatin) and aggregates up over the various strengths of its dosage forms (e.g., over 10, 20, 40 and $80 \mathrm{mg}$ strengths of an oral tablet). Different forms of a molecule (e.g., injectibles and oral tablets) constitute different 'molforms' and consequently different product markets. This definition implies that different manufacturers selling the same molform are competing in the same product market. It also implies different manufacturers selling different molecules that are used for the same or similar clinical purpose are not competing in the same product market. For example, the various oral tablet dosage strengths of the statin drug rosuvastatin (brand name crestor $^{\mathrm{TM}}$ ) used to treat LDL-cholesterol are in a different product market than the various oral tablet dosage strengths of the statin drug atorvastatin (brand name Lipitor ${ }^{\mathrm{TM}}$ ) also used to treat LDL-cholesterol.

Consequently, in our empirical framework, product markets are assumed to exhibit significant within market cross-price substitutability but limited between market cross-price substitutability. This definition generally conforms to product market definitions adopted by the FTC in enforcing its horizontal merger guidelines jointly developed with the DOJ (Whinston 2007). However, it is important to note that this 
economic price-substitutability defined market definition may not conform to product market conceptions used in clinical practice. For example, the statin drugs rosuvastatin and atorvastatin might be considered by some physicians as being clinically substitutable, although our approach deems them to be in separate product markets.

Additional details regarding variable definitions and analyses NSP defines a drug as being "generic" at the quarter-year the branded molform loses patent or other exclusivity. The data vendor's assignment of 'generic' to a molform does not imply that the product faces intra-molform competition from another manufacturer. There are two types of manufacturers marketing 'generic' molforms in our sample: manufacturers marketing the molform under the branded manufacturer's FDA approved NDA and ANDA. NSP designates the former 'branded'. Branded drugs are marketed either by the originator branded manufacturer or through a license to another manufacturer (e.g., Pfizer holds the NDA to market the molform Epipen ${ }^{\mathrm{TM}}$ and Pfizer has licensed to Mylan the right to market Epipen ${ }^{\mathrm{TM}}$. Mylan is the sole manufacturer of Epipen ${ }^{\mathrm{TM}}$ in our sample). The latter are commonly termed in the gray literature and in legal proceedings as 'authorized generics'(Berndt et al. 2007). NSP also designates a branded drug with LOE and facing same-molecule generic competition as a "branded generic" drug. 'Branded generics' 
include molforms that are slight reformulations of the originator product or combine the originator molecule with another already generic molecule(s) under the originator's NDA (so-called supplemental NDA). In our empirical framework, we enumerate brands, branded generics and generics available postLOE in our manufacturer count of a given product market and alternative estimates of within product market size. Branded generics and generics are both considered 'generics' in our analysis.

Our principal metrics for analyses are: (1) the number of unique manufacturers of a molform in a quarter-year; (2) the market size of a molform proxied by its quarterly and annual number of standard units sales volume and its inflation-adjusted sales revenues; and (3) two other product characteristics - the quarter and year of its original U.S. launch date (we term this drug 'vintage')(Lichtenberg 2009), and the product market's formulation which we interpret as a measure of its manufacturer's fixed and variable costs of production.

As a measure of sales volume, NSP reports "standard units" measuring the number of smallest dosage form single items (such as vials, syringes, bottles of tablets/capsules) contained in a unit or shipping package purchased by pharmacies or other distribution outlets. These units are 'standardized' to approximate per prescription volume comparisons between orally 
formulated and non-orally formulated drugs. Although "standard unit" is an inherently ambiguous metric, we are unaware of any better or more commonly utilized metric of drug product volume sold nation-wide (Berndt and Dubois 2016).

The "dollar sales" reported by NSP is the total amounts paid for purchases of a molform from a specific manufacturer by quarter, converted into $2016 \mathrm{Q} 1$ U.S. dollars using the Gross Domestic Implicit Price Deflator, indexed to 1.000 in $2016 Q 1$ ("Federal Reserve Board Economic Data" 2018). The invoice-based dollar metrics reflect the amounts paid by retail pharmacies, hospitals and clinics, whether purchased directly from a manufacturer or indirectly via a wholesaler or chain warehouse. Invoice line item discounts are included, but prompt-payment, bottom-line invoice and 340B discounts are excluded (Dusetzina et al. 2017; M. Aitken et al. 2016). Drug rebates paid by the manufacturer to an insurer or intermediary are not reflected in these invoiced revenues and are generally not publicly available. To the extent sales from wholesalers include wholesaler margins and exclude off-invoice rebates paid by manufacturers to pharmaceutical benefit managers (PBMs), third party payers, pharmacies and insurers, the NSP data overstate net revenues received by manufacturers. NSP contains two variables denoting "manufacturers", "Corp" and "Mnf". "Corp" is the alphanumeric name of the corporation, 
including its subsidiaries, identified on the sponsor-owned-FDAapproved label appearing in the orange Book (the NDA or ANDA applicant), while "Mnf" is the product's manufacturer, such as the "parent" corporation of a multi-corporation firm. Here we employ "Mnf" as the principal identity of generic drug supplier, although we also undertake sensitivity analyses utilizing "Corp". Our results are not materially different using "Corp" rather than "Mnf".

For each generic molform quarterly observation, we count the number of unique Mnfs having positive unit volumes during that quarter. We measure competition in each molform by the number of distinct manufacturers having positive sales volumes in that quarter. The number of competitors includes the branded or branded generic manufacturer for the molform when available.

We consider an entry to occur in the first period in which the Mnf makes a positive sale in the respective molform market, following at least one quarter of zero sales. Similarly, we consider an exit to occur at the last quarter year in which the Mnf makes a positive sale in the molform market, followed by one or more quarters of zero sales. When calculating quarterly entry and exit rates in quarter $t$, we define the denominator as the count of Mnfs in quarter t-1 aggregated over all molformMnfs. 
Market shares measured in standard unit volumes are similarly defined by molform. We aggregate standard unit volumes for each molform-manufacturer pair and for each molform. Molform-Mnf sales measured in standard unit volumes are then expressed as a fraction of total molform sales at time $t$. Shares are defined between $\odot$ and 100 where the max value is 100 .

Product market vintage is also defined by molform. This definition presents some challenges as drug launches occur at a molecule-dose-formulation level, yet we observe product markets at the molform level. Consequently, a product market may have multiple launch dates. To address this concern, we define the vintage of a product market as the earliest reported U.S. launch date for a given molform. This launch date is a variable reported by the data vendor, and corresponds to the year of the molform's launch into the U.S. market as a branded drug. This assignment rule worked well for the vast majority of product markets, $81.5 \%$ of the sample, where for the same molform a generic and a brand were observed in the dataset. For the remaining $18.5 \%$ of the sample, where no brand product was observed in the dataset or where the brand had a launch date that followed the generic, a manual search of the FDA's orange Book revealed that in most cases these products were very old drugs (approved in the 1950s or earlier) or combinations involving very old drugs. For these molforms absent further 
information, we faced the choice of identifying the product molform launch date as the earliest of (i) the launch date of the generic recorded in NSP ('Option 1'), or (ii) the launch date of the brand even if NSP indicated the launch date of the brand occurred after that of the generic ('Option 2'). In operationalizing these options, we found option 1 always entails a greater age than option 2, with the size of the age difference being small and stable. We chose to use option 2 for the main analysis. In sensitivity analyses, we used the Option 1 definition of product market vintage and reran all analyses. There were no material differences in results.

We identify five vintages among molform drug markets and assign each molform to one of five vintage cohorts in each year: $<15$ years; 15-19 years; 20-24 years; 25-34 years; and 35+ years. Thus, in 2004, the youngest cohorts contain products launched before 2004 - relatively recent, newly generic products - while the oldest set of cohorts in 2004 includes molforms launched before 1969 .

\section{RESULTS}

Sample Descriptive Statistics

517-652 manufacturers sold 1982-2655 unique branded and generic molforms between 2004-2016 (Table 1). The number of unique manufacturers and the number of unique molforms increased 
between 2004 and 2016. In all years, about half of unique molforms are oral (50\%), the remainder are split between injectible (22\%) and 'other' formulated drugs (27\%). Approximately two thirds of our full sample of 4,289 molforms (including non-unique molforms) are generics, the remainder are brands.

\section{INSERT TABLE 1}

The 2721 generic molforms in our sample can be further disaggregated into: (i) markets with a branded product but no branded generic $(n=801) ;(i i)$ markets with a branded generic but no branded product $(\mathrm{n}=334)$; and (iii) markets with no brand and no branded generic $(n=1586)$. Thus, generic drug markets with no branded competition are the most common generics in our sample and generic markets with a branded generic but no brand, are the least common in the sample. Moreover, generic molform markets with only a brand ( $n=1568$ from Table 1) occur with about the same frequency in our data as markets with no brand and no branded generic $(n=1586)$. In total, the sample includes 334 molform markets with a branded generic, $2387(801+1586)$ generic markets with no branded generic, and 1568 branded markets with no generic and no branded generic.

Brands comprise a larger share of annual sales revenue compared to generics in all years, but they decrease in 
importance over time from 83\% of annual sales revenue in 2004 to 74\% in 2016. While orally formulated generics comprise the largest category of generic sales revenue in all years, this share declines from $67 \%$ in 2004 to $49 \%$ in 2016 . At the same time, injectible and other formulated generic drugs become increasingly important to annual sales revenue: injectible sales revenue increase from $23 \%$ of total in 2004 to $38 \%$ in 2016 and other sales revenue increases from $10 \%$ in 2004 to $13 \%$ in 2016. The relatively rapid growing share of injectibles likely reflects the increasing launch and use of small molecule specialty drugs and biologics over our study period.

Finally, the descriptive statistics of standard unit volumes are opposite that of revenue shares. While branded and generic revenue shares average $76 \%$ and $24 \%$ between 2004 and 2016, branded standard unit volume shares average $23 \%$ and $77 \%$, respectively; both generic volume and generic revenue shares increase over time, while those for brands decline. In terms of formulations of total standard unit volumes, oral molforms steadily dominate at $78 \%$, others constitute a stable $21 \%$, and injectibles account for only $1 \%$.

Figure 1 reports generic product market ages over our study period. We find that the average generic drug age rises over our study time period from approximately 20 years in 2004 to 25 
years in 2016. Oral drugs match the overall trend, whereas nonoral drugs do not: injectible drugs exhibit an average age of approximately 18 years in 2004 and climb to 26 years in 2016 . other drugs are younger than oral and injectible drugs (approximately 15 years in 2004), appear to become slightly younger by 2013 and then age slightly back to about 17 years by 2016 .

\section{INSERT FIGURE 1}

With these drug characteristics as background, we now present four facts involving more disaggregated statistics on the sample.

FACT 1: Branded and Generic Drug Products Exhibit Substantial Churning (Entry and Exit)

Manufacturer entry and exit in drug markets is robust, particularly among generics. Table 2 displays quarterly exit and entry rates separately for branded and generic product markets. The numbers in the cells are percentages and each percentage point corresponds to about 60-70 absolute quarterly entrants or exits. On average, entry rates are about 3 percent for generics, 1 percent for brands, and for exit rates, about 2 percent for generics and 1 percent for brands. Entry rates in both branded and generic product markets are greater than exit rates and increase over time, but recently entry rates have fallen and exit rates have increased. 


\section{INSERT TABLE 2}

Greater entry/exit upheaval and churning appears to occur in generic compared to branded drug markets. Specifically, total quarterly churn (entry plus exit) rates are non-trivial and exhibit relative stability at about 4 to 5 percent, but the entry vs. exit composition differs between branded and generic product markets: branded entry rates are slightly U-shaped over time, while branded exit rates fall until about 2013 and then increase thereafter. In contrast, generic entry rates increase from 2006 until 2013, and then decrease, while generic exit rates generally increase until 2011, and are flat thereafter. The total brand plus generic entry rate falls from about 6 percent in 2004 to under 4 percent in 2016, while the total brand plus generic exit rate increases from about 3 percent in 2004 to 4 percent in 2011, and then falls to about 3.5 percent. 3

Any observed entry breaks in Table 2 occur between 2011 and 2013, coinciding with the "patent cliff" in 2011-2012 as a large number of "blockbuster" drugs lost patent and other exclusivities, and implementation of Generic Drug User Fee

Amendment Acts (GDUFA-I) in 2013 (Berndt, Conti, and Murphy 2018). While the difference between brand and generic entry rates is much smaller in 2016 than earlier, the difference in 
brand and generic exit rates is observed to increase substantially beginning around 2011.

FACT 2: Generic Drugs Commonly Sold in the U.S. are Increasingly older Products

In Figure 2, we report volume-weighted shares for each molform in the five vintage cohorts. In all years, the greatest volume share is achieved by the two oldest cohorts of generic drugs - molforms age 25 through 34 years and molforms aged 35 years and older. In addition, volume shares of these oldest products have increasingly dominated domestic generic markets. Specifically, the sum of volume shares attained by the two oldest vintage cohorts of generic drugs was about 52 percent in 2004 and almost 75 percent by 2016. Moreover, around 2009, the volume shares of molforms aged 25 through 34 years appeared to dramatically decrease in volume, while those aged 35 and older increased in volume.

\section{INSERT FIGURE 2}

The volume share of the youngest generic product markets is not only the smallest of the five vintage cohorts, it appears to be getting even smaller over time; in 2004 the volume share of generic product markets under 15 years was about 9 percent, in subsequent years it rose slightly to about 10 percent, and by 2016 it had fallen to less than 3 percent. Volume shares 
attained by the second youngest cohort of generic product markets (15-19 years) did not fare much better, beginning at about 14 percent in 2004, increasing to just over 18 percent in 2010, and then falling back to about 9 percent in 2016. The volume share of the middle aged generic product markets (ages 20-24) was generally stable after 2006, increasing slightly from about 13 percent in 2006 to about 16 percent in 2016 .

In summary, newly genericized drug products have not been that successful in penetrating U.S. generic markets. This is in rather marked contrast to the older cohorts of generic drug whose U.S. volume shares have grown quite steadily over time.

Finally, as seen in Appendix Figure $\boldsymbol{A} 1$ these vintage trends in volume shares observed over all formulations are similar to those occurring for orally formulated molforms. In contrast, the oldest cohorts among the injectible and especially the other molforms do not increasingly dominate volume shares, but instead it is the second oldest and middle age vintage cohorts among these formulated generic drug products that increase in volume share over time. The youngest cohorts ( $<15$ years) fare the poorest in garnering volume market share overall and across each of the product formulations. 
FACT 3: Competition in Generic Molform Markets is Typically Limited and is More Robust Among older Compared to Younger Product Markets

We calculate the mean and interquartile range of number of manufacturers by molform vintage cohort, and display these calculated values in Table 3.

INSERT TABLE 3

As measured by means (Table 3), competition among generic manufacturers is most intense for the oldest cohorts of generic drugs, and least intense for the youngest generic drug cohorts. At about 7 , the mean number of manufacturers for the oldest drugs (35+ years) is larger than for any other vintage cohort, and at about 2 manufacturers, it is smaller for the youngest (< 15 years) than for any other vintage cohort. However, for the oldest (35+ years), second oldest (25-34) and youngest $(<15$ years) vintage cohorts the mean number of manufacturers is falling over time, while for the younger but not youngest (15-19 years) and middle age (20-24 years) generic drugs the mean number of manufacturers generally increases over time. After 2012, the mean number of competitors in the 15-19 year and 20-24 year vintage cohorts is greater than that for the 25-34 year cohort. After 2013 the mean number of competitors for the 15-19 and 20-24 year cohorts reaches between 5 and 6 , with at 6 the 
20-24 year cohort facing almost as many competitors as the oldest $(35+$ years) cohort.

In each time period, median values for each vintage cohort are generally smaller than their corresponding mean values. However, we do observe some differences across vintage cohorts. The median number of manufacturers in the oldest vintage cohort, at between 4 and 6 , is only slightly smaller than the corresponding mean number of manufacturers which range from above 6 to almost 8 . In contrast, for the youngest vintage cohort (< 15 years), the median number of manufacturers is 1 throughout the 2004-2016 time period, while the mean number of competitor manufacturers is relatively stable at about 2 - twice the median value. Hence the ratio of mean to median is largest for the youngest vintage, and smallest for the oldest vintage, with the other vintages having mean/median ratios in between.

In summary, the extent of competition is greatest for the oldest cohorts of drugs (35+ years) and is smallest for the youngest cohort ( $<15$ years). Indeed, with a median of but 1 competitor, for the youngest cohort the extent of competition is very limited.

To evaluate whether this characterization of competition also holds for each molform formulation, in Appendix Table A1 we report the annualized mean and interquartile range of 
manufacturer counts in each vintage cohort separately by formulation .

For the most populous oral formulations, although time trends are not monotonic, mean numbers of competitors are larger in 2016 than in 2004 for the three intermediate vintages, but for the youngest ( $<15$ years) and oldest (35+ years) vintages the mean numbers are smaller in 2016 than in 2004. Across all vintages, the mean number of competitors is largest in the oldest vintage and smallest in the youngest vintage. In all vintages, the median number of competitors is less than the mean, with medians relatively stable in the $<15$ year, 25-34 years, and $35+$ year vintages, but increasing in the intermediate 15-19 year and 20-24 year vintages.

For injectable formulations, again time trends are not monotonic, means and medians are quite similar for all vintages, with the ratio of mean to median evaluated at overall averages being less than 2 for all vintages.

For other formulations, only for the oldest cohort (35+ years) are time trends in mean and median number of manufacturers monotonic, with the oldest generic drug vintage cohort facing a smaller number of competitors over time. 
FACT 4: Manufacturer Generic Drug Product Market Annual Revenues are Typically Small, are Largest among Younger Generic Drugs, but are Heavily Right Skewed

Table 4 reports mean, median and interquartile range of annual revenues per generic molform-Mnf (in thousands) overall and by formulation.

We observe that in early years, median annual sales revenues are $\$ 500 \mathrm{~K}-\$ 600 \mathrm{~K}$, they rise steadily and by 2016 have almost tripled to about $\$ 1.5$ million in 2016 . In contrast, the $25^{\text {th }}$ percentile annual sales are relatively stable from 2004 through 2013, ranging between \$36K - \$56K, but then increase more sharply, doubling and reaching $\$ 110 \mathrm{~K}$ in 2016 . The $75^{\text {th }}$ percentile annual sales are relatively stable between $\$ 4.0$ $\$ 4.7$ million through 2010 , then increase more rapidly between 2011 and 2013 to about $\$ 5.4$ - 6.8 million and then hold steady at about $\$ 8$ million thereafter.

\section{INSERT TABLE 4}

More striking is that in every year mean revenues per molform-Mnf are at least several times larger than even at the $75^{\text {th }}$ percentile, indicating that sales revenues per molform-Mnf are extremely right-skewed. In the early years, annual mean sales revenues were about 2.3 to 2.8 times larger than at the $75^{\text {th }}$ percentile, and even as the $75^{\text {th }}$ percentile level of sales 
increased sharply in 2011-2013, so too did the mean, which by 2016 was just over $\$ 15$ million annually.

Again in all three product formulations, sales revenues per molecule-manufacturer are highly right-skewed, with the difference between mean and median being the largest in the other formulation. In all years, injectible generic drug product markets exhibit larger median, mean and $75^{\text {th }}$ percentile annual sales revenue per manufacturer compared to oral and other formulated drugs. In summary, the aggregate trends in sales revenue per molecule-manufacturer appear to be driven largely by orals and injectibles.

Table 5 reports these annual revenue statistics disaggregated by product market vintage.

\section{INSERT TABLE 5}

A striking finding is that while for all vintages except the youngest, the ratio of mean annual revenues to median annual revenues, evaluated at the average over all years, ranges between 12 and 17, indicating substantial skewness. However, for the youngest cohort - those $<15$ years - this mean/median ratio reaches an astonishing value of about 30 . Thus, it is in the youngest vintage of generic drugs where the dispersion in annual revenues is relatively largest - a very few recent vintage generic drugs are extremely successful, but most are 
not. Indeed, as seen in Table 5, for the youngest vintage, median annual revenues have fallen by over $50 \%$ between 2004 and 2016 , from $\$ 875,000$ to $\$ 371,000$. In contrast, for the oldest vintage, between 2004 and 2016 median annual revenues have grown four-fold - from $\$ 351,000$ to $\$ 1.44$ million.

In terms of mean annual revenues, for the three oldest vintages, there have been steady increases up through 2013-2014 followed either by stable or slightly declining trends. Peak annual mean revenues occurred earlier for the younger vintages in 2006 for the youngest (< 15 years) and in 2011 for the younger (15-19 years) vintage.

Hence, all generic drug vintage cohorts exhibit substantial right skewness, and a small number of very successful generic molforms make mean revenues look much more attractive than median values. However, it is the younger generic drug market vintages that display the most enormous heterogeneity in annual revenue streams. In general but especially in recent years, older generic vintage drugs have experienced greater revenue growth than have the younger vintages. 


\section{DISCUSSION}

The four descriptive facts about U.S generic product markets we report in this study raise several issues important for further empirical evaluation and policy discussion.

First, we report that considerable product churning (exit and entry) occurs, with entry rates decreasing and exit rates increasing in recent years. This raises the question of what role, if any, the Generic Drug User Fee program has had in creating barriers to entry and incentives to exit. Berndt, Conti and Murphy (2018) examined the changing features embodied in the GDUFA-I (2013) and GDUFA-II (2017) using recently released public data from the FDA (Berndt, Conti, and Murphy 2018). The analysis of that data yielded three findings: (i) generic drugs and their base ingredients are increasingly and overwhelmingly manufactured outside the U.S.; (ii) most ANDA sponsors hold small portfolios of ANDAs with the median number being one. However, a small number of ANDA sponsors each holds hundreds if not thousands of ANDAs. In 2017, the largest 1 percent of ANDA portfolio holders accounted for 5,475 of the 7,966 (68.7 percent) claimed approved ANDAs; (iii) The fee structure of GDUFA-I (set per drug and per establishment and levied annually) likely erected barriers to entry, and created scale and scope economies for incumbent manufacturers. User 
fees were changed under GDUFA II in part to mitigate these incentives. The authors hypothesized that the GDUFA I fee schedule may have created incentives for existing generic manufacturers to consider exiting drug markets, particularly when annual product revenues did not outweigh the new fixed costs imposed by GDUFA I annual fees. The increase in exit rates reported in this paper is consistent with the observed recent decline in the number of net active manufacturing facilities, based on manufacturer voluntarily-supplied data to the FDA. Future research that examined these questions empirically could shed light on the effects of regulatory policies on U.S. generic product markets.

Second, our finding that over the entire 2004-2016 time period, the number of generic manufacturers per molform is typically two or smaller across product vintages and formulations suggests that mature U.S. generic drug markets should be considered in steady state typically to involve only a small number of generic competitors. This analysis extends preliminary research (Berndt, Conti, and Murphy 2017) in which we reported that aggregated over all generic product vintage cohorts, the distribution of the number of manufacturers was right-skewed, with a small number of molforms having extremely large number of competitors, resulting in the mean number of competitors being considerably larger than the median. 
These findings contrast sharply with evidence presented by previous studies suggesting generic competition is significant, commonly involving four or more suppliers in the first 24 months after loss of patent protection and other exclusivities (Berndt and Aitken 2011; Berndt and Newhouse 2012). The research findings reported here are also generally consistent with recently published research based on selected claims data encompassing a more limited set of generic drug markets (Dave et al. 2017) .

Over the last few years policy makers and the FDA have raised concerns regarding the adequacy of competition among selected generic drug markets. These discussions have led to the FDA implementing policies to encourage more competition whenever the number of generic competitors is less than three (U.S. Food and Drug Administration 2017). Our findings suggest increased FDA scrutiny over markets with limited competition may be a larger task than commonly appreciated.

Third, we find that the revenues received for a small number of generic drug products by their manufacturers appears to have been much larger than for most generic products. The occurrence of this phenomenon in the last decade suggests the possibility that relatively high revenue generic drugs might concentrate among those awarded 180-day exclusivity from 
successful patent challenges and thus face no or only an "authorized" generic competitor. Certain older products enjoying high revenues might be those with no competitors, slight reformulations of older pioneer products that confer some advantages to consumers or prescribers, or those benefiting from price increases during shortages due to temporary exits for which demand still exists.

From a regulator's perspective, it could well prove challenging to sustain or encourage competition in generic drug markets where the underlying reason for limited suppliers is very strong brand loyalty to the 'improved' line extension product, or slack demand due to therapeutic obsolescence, regardless of product vintage. To contribute to a better understanding of supply dynamics and their amenability to potential policy intervention, it would be useful if future research examined in detail revenue outliers (revenues in the $75^{\text {th }}$ percentile or higher and in the $25^{\text {th }}$ percentile or lower) relative to the mean and median by vintage cohorts and their characteristics. Another potentially informative investigation could involve a decomposition into various therapeutic classes, such as oncology, respiratory, infectious disease, and neurodegenerative illnesses (Berndt, Conti, and Murphy 2017). 
Lastly, an intriguing issue raised here relates market competition to drug price increases. Previous research has reported high and growing prices among selected generic drugs, related to a limited number of manufacturers (Collins and McCaskill 2016; Alpern, Stauffer, and Kesselheim 2014; Silverman 2014). Given the limited and possibly declining generic molecule competition we observe generally, why have prices for generic drugs not risen more rapidly than has been observed?

Two hypotheses come to mind. First, the increased consolidation in recent years from merger and acquisition activity involving wholesaler purchasers, retail chains, insurers and PBM firms may have increased demand side buying power, putting downward pressure on generic manufacturers' prices. By exercising this increased monopsonistic buying power and combining it with PBMs' powerful utilization management tools, purchasers may increasingly be able to play generic manufacturers off against each other, intensifying generic price competition .

Second, it may be that many generic molecule markets are contestable, whereby firms hold an option to enter or re-enter. In contestable markets, the threat of entry disciplines incumbent firms, resulting in pricing outcomes that resemble highly competitive, multi-manufacturer markets, even when the number of actual competitors is small. ${ }^{4}$ Once a generic 
manufacturer receives an approved ANDA, it can retain it indefinitely even if it temporarily discontinues producing the product. The threat of reentry by temporary exiting firms might facilitate contestability. This possibility and the role of the Generic Drug User Fee legislation in 2013 and 2017 in affecting temporary or permanent exit merit more research.

In summary, U.S. generic molecule markets typically experience substantial entry and exit "churn" rates, generating surprisingly modest annual revenues (although in recent years a small number of molform markets have earned substantial revenue streams). The median number of generic manufacturers in molform markets is between 2 and 3 indicating that U.S. generic molecule markets are highly concentrated and that manufacturers typically face very limited competition. Although much recent attention has been placed on generic entry and use patterns among newer generic drugs, the most commonly used generic drug products are older drugs, many of which launched in the 1990s 'blockbuster' era. The research findings reported here suggest that dynamic patterns of entry, exit, and revenues achieved by generic prescription drugs in U.S. markets are complex, vary by vintage, and are worthy of further scrutiny. 


\section{Notes}

${ }^{1}$ These authors use MarketScan ${ }^{\text {TM }}$ retrospective claims data to examine prices and market competition for drugs classified as either single or multi-source between 2008-2013, excluding entry and exit of new brands, and entry of generics following the brand's loss of exclusivity between 2008-2013. The data contain retail and mail order pharmacy claims, but likely understate sales through long term care, hospital, and federal facility channels.

${ }^{2}$ The FDA's Orange Book identifies the ANDA applicant, noting the actual manufacturer may differ from the ANDA applicant (also called labeler) due to manufacturing outsourcing to contract manufacturers. The ANDA applicant may differ from the marketer, due to licensing actions. Our use of the term "supplier" should therefore be interpreted as the entity selling and marketing a molecule dosage form.

${ }^{3}$ Based on manufacturer-supplied data reported to the FDA, Berndt ER, Conti RM, Murphy SJ, 2018, op. cit., find that the number of net active pharmaceutical ingredient and final dosage form manufacturing facilities has declined between 2013 and 2017 .

${ }^{4}$ For further discussion on contestable markets, and possible resemblance of US generic drug markets to contestable markets, see Economics Online, Contestable Markets, 2017. Available from:

http://WwW.economicsonline.co.uk/Business_economics/Contestable_ markets.html.

\section{References}

Aitken, Murray, Ernst R. Berndt, David Cutler, Michael Kleinrock, and Luca Maini. 2016. "Has the Era of Slow Growth for Prescription Drug Spending Ended?" Health Affairs 35(9):1595-1603.

Aitken, Murray L., and Michael Kleinrock. 2018. "Medicines Use and Spending in the U.S.: A Review of 2017 and Outlook to 2022." Parsippany, NJ: IQVIA Institute for Human Data Science. https://www.iqvia.com//media/iqvia/pdfs/institute-reports/medicine-use-andspending - in - the-us-a-review- of - 2017 - and-outlook - to 2022. pdf. 
Alpern, Jonathan D., William M. Stauffer, and Aaron S. Kesselheim. 2014. "High-Cost Generic Drugs-Implications for Patients and Policymakers." New England Journal of Medicine 371(20): 1859-1862.

Berndt, Ernst R., and Murray L. Aitken. 2011. "Brand Loyalty, Generic Entry and Price Competition in Pharmaceuticals in the Quarter Century after the 1984 Waxman-Hatch Legislation." International Journal of the Economics of Business 18(2): 177-201.

http://proxy.uchicago .edu/login?url=http://search . ebscohost . com/login . aspx?direct $=$ true $\& d b=e o h \& A N=1262154 \&$ site=ehost live\&scope=site.

Berndt, Ernst R., Rena M. Conti, and Stephen J. Murphy. 2017. "The Landscape of US Generic Prescription Drug Markets, 2004-2016." National Bureau of Economic Research, Working Paper No. 23640.

- 2018. "The Generic Drug User Fee Amendments: An Economic Perspective." Journal of Law and the Biosciences 5 (1): 103-141.

Berndt, Ernst R., and Pierre Dubois. 2016. "Impacts of Patent Expiry and Regulatory Policies on Daily Cost of Pharmaceutical Treatments: OECD Countries, 2004-2010." International Journal of the Economics of Business 23(2): 125-47.

https ://doi.org/ttps ://doi.org/10.1080/13571516.2015.112296 9 .

Berndt, Ernst R., Richard Mortimer, Ashoke Bhattacharjya, Andrew Parece, and Edward Tuttle. 2007. "Authorized Generic Drugs, Price Competition, and Consumers' Welfare." Health Affairs 26(3): 790-799.

Berndt, Ernst R., and Joseph P. Newhouse. 2012. "Pricing and Reimbursement in U.S. Pharmaceutical Markets." In The oxford Handbook of the Economics of the Biopharmaceutical Industry, Danzon PM, Nicholson S, editors, 201-65. New York, NY: Oxford University Press.

Collins, Susan M., and Claire McCaskill. 2016. "Sudden Price Spikes in Off-Patent Prescription Drugs, The Monopoly Business Model That Harms Patients, Taxpayers, and the US Health Care System." 114-429. Washington, DC: U.S. Government Publishing Office. 
https://WWw. congress.gov/114/crpt/srpt429/CRPT114srpt429.pdf.

Conti, Rena M., and Ernst R. Berndt. 2014. "Specialty Drug Prices and Utilization After Loss of U.S. Patent Exclusivity, 2001-2007."

http://proxy.uchicago.edu/login?url=http://search.ebscohost . com/login . aspx?direct $=$ true\&db=eoh\&AN=1440021\&site=ehost live\&scope=site.

Dave, Chintan V., Aaron S. Kesselheim, Erin R. Fox, Peihua Qiu, and Abraham Hartzema. 2017. "High Generic Drug Prices and Market Competition: A Retrospective Cohort Study." Annals of Internal Medicine 167(3):145-151.

https://doi.org/10.7326/M16-1432.

Drake, Keith M., and Thomas G. McGuire. 2016. "Stock Price Evidence For Anticompetitive Effects In The Nexium 'Reverse-Payment' Settlement." Journal of Competition Law \& Economics 12(4):735-747.

Drake, Keith M., Martha A. Starr, and Thomas G. McGuire. 2015. "Do 'Reverse Payment' Settlements Constitute an Anticompetitive Pay-for-Delay?" International Journal of the Economics of Business 22(2):173-200.

Dusetzina, Stacie B., Rena M. Conti, L. Yu Nancy, and Peter B. Bach. 2017. "Association of Prescription Drug Price Rebates in Medicare Part D with Patient Out-of-Pocket and Federal Spending." JAMA Internal Medicine 177(8):1185-1188.

"Federal Reserve Board Economic Data." 2018. Federal Reserve Bank of St. Louis. 2018. https://fred.stlouisfed.org/series/A191RI1Q225SBEA.

Lichtenberg, Frank R. 2009. "International Differences in Cancer Survival Rates: The Role of New Drug Launches." International Journal of Healthcare Technology and Management 10(3):138-155.

McGuire, Thomas, Keith Drake, Einer Ethauge, Raymond Hartman, and Martha Starr. 2016. "Resolving Reverse-Payment Settlements with the Smoking Gun of Stock Price Movements." Iowa Law Review 101(4):1581-99.

Silverman, Ed. 2014. "Lawmakers Probe 'Staggering' Price Hikes for Generic Drugs." Wall Street Journal, October 2, 2014. 
https://blogs.wsj . com/pharmalot/2014/10/02/lawmakers-probestaggering-price-hikes-for-generic-drugs/.

U.S. Department of Health and Human Services. 2018. "American Patients First." Washington, DC: U.S. Department of Health and Human Services.

https://wWw.hhs.gov/sites/default/files/AmericanPatientsFir st.pdf.

U.S. Food and Drug Administration. 2017. "FDA Tackles Drug Competition to Improve Patient Access: Agency Takes Important Steps under New Drug Competition Action Plan." U.S. Food and Drug Administration. June 27, 2017. https://www.fda.gov/NewsEvents/Newsroom/PressAnnouncements/ ucm564725.htm.

Whinston, Michael D. 2007. "Antitrust Policy Toward Horizontal Mergers." In Handbook of Industrial Organization, 3:23692440. Amsterdam: North Holland Elsevier. 
FIGURE 1: MOLFORM MEAN AGE OVERALL AND BY FORMULATION

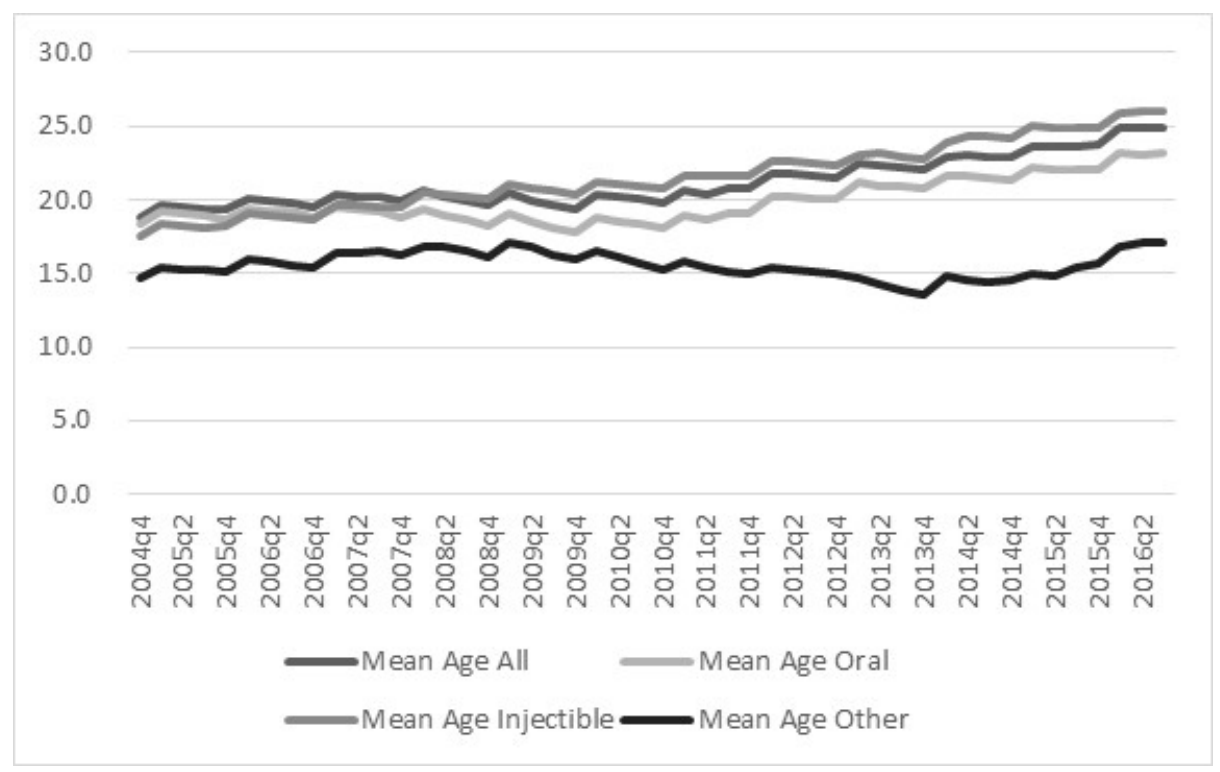

SOURCE: Authors' calculations based on IQVIA's National Sales Perspective (NSP) database, 2004Q4 - 2016 Q3.

FIGURE 2: MOLFORM VOLUME SHARE BY VINTAGE

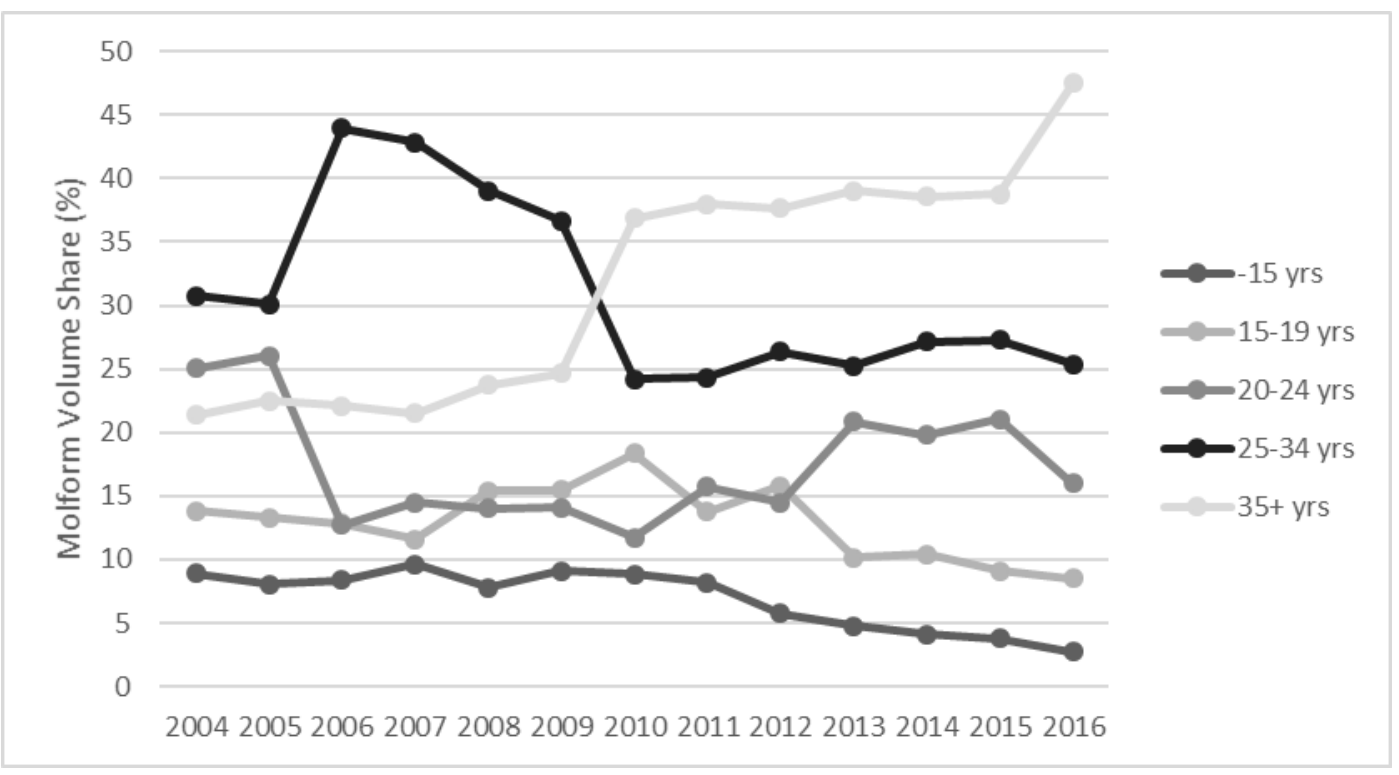

SOURCE: Authors' calculations based on IQVIA's National Sales Perspective (NSP) database, 2004Q4 - 2016 Q3. NOTES: Mnf (manufacturer) is the generic supplier. Generics include both multi-source and branded generics. An entry occurs in the first period in which the Mnf has a positive sale in the respective molform market. An exit occurs at the last quarter year in the Mnf has a positive sale in the molform market. The numbers in the cells are percentages, each percentage point corresponds to about 60-70 absolute quarterly entrants or exits. 
TABLE 1: CHARACTERISTICS OF PRESCRIPTION DRUGS IN ANALYTIC SAMPLE

$$
\text { MOLFORM COUNTS }
$$

\section{REVENUE STATISTICS}

Annual (\$MIL) Branded (\%) Generic (\%) Oral (\%) Injectible (\%) Other (\%)

YEAR \# Total \# Branded \# Generic \# Orals \# Injectables \# Others \# Mnfs

\begin{tabular}{|l|l|l|l|l|l|l|l|l|}
2004 & 1982 & 1061 & 1346 & 1026 & 545 & 411 & 517 & 295121 \\
\hline
\end{tabular}

\begin{tabular}{|l|l|l|l|l|l|l|l|l|}
2005 & 2076 & 1100 & 1427 & 1068 & 563 & 445 & 545 & 296143 \\
\hline
\end{tabular}

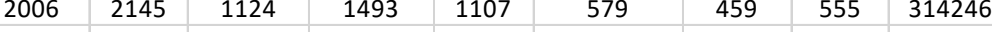

\begin{tabular}{|l|l|l|l|l|l|l|l|l|}
2007 & 2179 & 1129 & 1537 & 1132 & 584 & 463 & 565 & 317694 \\
\hline
\end{tabular}

\begin{tabular}{|l|l|l|l|l|l|l|l|l|}
\hline 2008 & 2248 & 1111 & 1625 & 1178 & 586 & 484 & 562 & 317485 \\
\hline
\end{tabular}

\begin{tabular}{|l|l|l|l|l|l|l|l|l|}
\hline 2009 & 2356 & 1116 & 1734 & 1236 & 605 & 515 & 572 & 331864 \\
\hline 2010 & 2415 & 1114 & 1804 & 1242 & 613 & 560 & 583 & 345567 \\
\hline
\end{tabular}

\begin{tabular}{l|l|l|l|}
2010 & 2415 & 1114 & 1804 \\
\hline
\end{tabular}

\begin{tabular}{|l|l|l|l|l|l|l|l|l|}
2011 & 2476 & 1126 & 1866 & 1254 & 622 & 600 & 589 & 351557 \\
\hline
\end{tabular}

\begin{tabular}{|l|l|l|l|l|l|l|l|l|}
\hline 2012 & 2481 & 1126 & 1883 & 1209 & 626 & 646 & 609 & 334015 \\
\hline 2013 & 2594 & 1146 & 1991 & 1191 & 631 & 772 & 621 & 343254 \\
\hline
\end{tabular}

\begin{tabular}{ll|l|l|l|}
2594 & 1146 & 1991 & 1191 & 631 \\
2627 & 1197 & 1989 & 1212 & 647
\end{tabular}

\begin{tabular}{|l|l|l|l|l|l|l|l|l|}
2015 & 2655 & 1232 & 2000 & 1216 & 657 & 782 & 652 & 428242 \\
\hline
\end{tabular}

\begin{tabular}{|l|l|l|l|l|l|l|l|l|}
\hline 2016 & 2550 & 1220 & 1906 & 1195 & 662 & 693 & 651 & 446400 \\
\hline
\end{tabular}

\begin{tabular}{|l|l|l|l|l|l|l|l|l|}
\hline Overall & 3488 & 1568 & 2721 & 1755 & 775 & 958 & 898 & 346693 \\
\hline
\end{tabular}

SOURCE: Authors' calculations based on IQVIA's National Sales Perspective (NSP) database, 2004Q4 - 2016 Q3.

\section{VOLUME STATISTICS}

Annual Branded (\%) Generic (\%) Oral (\%) Injectible (\%) Other (\%)

\begin{tabular}{l|l|l|}
208351 & 37 &
\end{tabular}

208342

215277

219504

221111

232081

235300

237492

223919

229928

230897

236742

239074

2721985

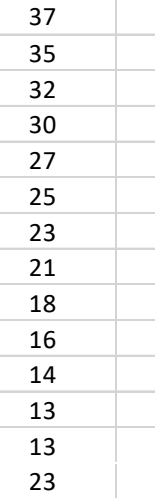

\begin{tabular}{|l|l|l|l|}
63 & 77 & 1 & 22 \\
\hline 65 & 76 & 1 & 23 \\
\hline 68 & 77 & 1 & 22 \\
\hline 70 & 77 & 1 & 22 \\
\hline 73 & 77 & 1 & 22 \\
\hline 75 & 77 & 1 & 21 \\
\hline 77 & 78 & 1 & 21 \\
\hline 79 & 78 & 1 & 21 \\
\hline 82 & 78 & 1 & 21 \\
\hline 84 & 78 & 1 & 21 \\
\hline 86 & 78 & 1 & 21 \\
\hline 87 & 78 & 1 & 21 \\
\hline 87 & 78 & 1 & 21 \\
77 & 78 & 1 & 21 \\
\hline
\end{tabular}


TABLE 2: CHURN RATE (\%) OF ACTIVE MNF-MOLECULE PAIRS OVER ALL FORMULATIONS AMONG GENERICS AND BRANDS

\begin{tabular}{|c|c|c|c|c|c|}
\hline \multirow{3}{*}{$\begin{array}{l}\text { Year } \\
2004\end{array}$} & \multirow{3}{*}{$\begin{array}{c}\text { Quarter } \\
\text { Q4 }\end{array}$} & \multicolumn{2}{|c|}{ GENERIC } & \multicolumn{2}{|c|}{ BRAND } \\
\hline & & Exit Rate (\%) & Entry Rate (\%) & Exit Rate (\%) & Entry Rate (\%) \\
\hline & & 1.61 & & 2.09 & \\
\hline 2005 & Q1 & 1.30 & 4.93 & 0.73 & 4.83 \\
\hline 2005 & Q2 & 2.16 & 3.63 & 0.64 & 2.48 \\
\hline 2005 & Q3 & 1.37 & 3.09 & 1.19 & 2.28 \\
\hline 2005 & Q4 & 1.56 & 3.13 & 1.28 & 1.55 \\
\hline 2006 & Q1 & 1.31 & 3.03 & 1.44 & 2.44 \\
\hline 2006 & Q2 & 1.23 & 2.54 & 0.46 & 1.09 \\
\hline 2006 & Q3 & 2.23 & 2.41 & 0.54 & 1.97 \\
\hline 2006 & Q4 & 1.47 & 2.99 & 0.81 & 1.25 \\
\hline 2007 & Q1 & 1.36 & 2.26 & 1.25 & 0.81 \\
\hline 2007 & Q2 & 1.56 & 2.64 & 1.26 & 1.17 \\
\hline 2007 & Q3 & 1.57 & 3.26 & 0.90 & 0.81 \\
\hline 2007 & Q4 & 1.83 & 2.29 & 1.34 & 0.99 \\
\hline 2008 & Q1 & 1.71 & 3.72 & 0.72 & 0.45 \\
\hline 2008 & Q2 & 2.27 & 2.66 & 0.90 & 0.99 \\
\hline 2008 & Q3 & 2.24 & 3.40 & 1.82 & 0.55 \\
\hline 2008 & Q4 & 2.49 & 2.98 & 1.94 & 0.65 \\
\hline 2009 & Q1 & 2.52 & 2.92 & 1.21 & 1.21 \\
\hline 2009 & Q2 & 2.21 & 3.04 & 0.65 & 1.12 \\
\hline 2009 & Q3 & 2.29 & 3.20 & 1.50 & 0.84 \\
\hline 2009 & Q4 & 2.34 & 3.19 & 1.87 & 0.94 \\
\hline 2010 & Q1 & 1.99 & 2.73 & 0.95 & 1.05 \\
\hline 2010 & Q2 & 2.28 & 3.02 & 0.58 & 0.29 \\
\hline 2010 & Q3 & 2.14 & 2.91 & 0.76 & 0.76 \\
\hline 2010 & Q4 & 2.92 & 3.05 & 0.38 & 1.33 \\
\hline 2011 & Q1 & 1.81 & 2.89 & 0.95 & 0.85 \\
\hline 2011 & Q2 & 3.21 & 3.47 & 1.41 & 1.32 \\
\hline 2011 & Q3 & 2.56 & 2.65 & 0.76 & 1.23 \\
\hline 2011 & Q4 & 2.34 & 2.84 & 0.75 & 0.57 \\
\hline 2012 & Q1 & 2.53 & 3.09 & 0.85 & 1.13 \\
\hline 2012 & Q2 & 2.08 & 3.41 & 0.85 & 0.75 \\
\hline 2012 & Q3 & 2.11 & 3.06 & 1.03 & 0.94 \\
\hline 2012 & Q4 & 2.60 & 3.93 & 0.84 & 0.75 \\
\hline 2013 & Q1 & 2.30 & 4.18 & 0.28 & 0.94 \\
\hline 2013 & Q2 & 2.32 & 3.28 & 0.82 & 2.01 \\
\hline 2013 & Q3 & 1.96 & 2.68 & 0.82 & 0.46 \\
\hline 2013 & Q4 & 2.17 & 2.56 & 0.36 & 1.64 \\
\hline 2014 & Q1 & 2.41 & 2.92 & 0.90 & 1.08 \\
\hline 2014 & Q2 & 2.00 & 2.48 & 0.45 & 1.70 \\
\hline 2014 & Q3 & 2.85 & 2.57 & 0.97 & 1.32 \\
\hline 2014 & Q4 & 2.18 & 2.53 & 0.61 & 2.09 \\
\hline 2015 & Q1 & 2.28 & 3.00 & 1.29 & 1.38 \\
\hline 2015 & Q2 & 2.82 & 2.93 & 1.04 & 0.61 \\
\hline 2015 & Q3 & 2.71 & 2.36 & 1.38 & 1.29 \\
\hline 2015 & Q4 & 2.29 & 2.40 & 1.35 & 2.20 \\
\hline 2016 & Q1 & 2.95 & 2.08 & 2.37 & 0.76 \\
\hline 2016 & Q2 & 3.28 & 2.37 & 3.79 & 1.35 \\
\hline 2016 & Q3 & & 2.26 & & 0.42 \\
\hline
\end{tabular}

SOURCE: Authors' calculations based on IQVIA NSP data, 2004Q4 - $2016 Q 3$. 


\section{TABLE 4: MEAN, MEDIAN AND INTERQUARTILE RANGE OF MOLFORM ANNUAL REVENUES OVER ALL FORMULATIONS AND BY FORMULATION}

\begin{tabular}{|c|c|c|c|c|c|c|c|c|c|c|c|c|c|c|c|c|}
\hline \multirow[b]{3}{*}{ YEAR } & \multicolumn{16}{|c|}{ Molform Revenue (in thousands) } \\
\hline & \multicolumn{4}{|c|}{ Overall Formulations } & \multicolumn{4}{|c|}{ Oral } & \multicolumn{4}{|c|}{ Injectible } & \multicolumn{4}{|c|}{ Other } \\
\hline & Mean & Median & 25-pctile & 75-pctile & Mean & Median & 25-pctile & 75-pctile & Mean & Median & 25-pctile & 75-pctile & Mean & Median & 25-pctile & 75-pctile \\
\hline 2004 & 9279 & 534 & 36 & 3979 & 8703 & 452 & 42 & 3979 & 12164 & 1635 & 182 & 3979 & 9051 & 323 & 8 & 3979 \\
\hline 2005 & 9714 & 539 & 42 & 4074 & 8963 & 450 & 46 & 4074 & 12266 & 1832 & 228 & 4074 & 10298 & 357 & 11 & 4074 \\
\hline 2006 & 10497 & 554 & 49 & 3998 & 9724 & 442 & 51 & 3998 & 12512 & 1848 & 246 & 3998 & 11590 & 381 & 11 & 3998 \\
\hline 2007 & 10723 & 572 & 52 & 4081 & 9832 & 457 & 49 & 4081 & 12822 & 1764 & 345 & 4081 & 12231 & 468 & 13 & 4081 \\
\hline 2008 & 10561 & 581 & 53 & 3949 & 9672 & 420 & 47 & 3949 & 12904 & 1870 & 357 & 3949 & 11870 & 495 & 17 & 3949 \\
\hline 2009 & 11429 & 617 & 57 & 4203 & 10319 & 475 & 52 & 4203 & 14539 & 1827 & 294 & 4203 & 12828 & 569 & 19 & 4203 \\
\hline 2010 & 12853 & 666 & 56 & 4681 & 11633 & 501 & 51 & 4681 & 16411 & 1862 & 314 & 4681 & 14171 & 654 & 19 & 4681 \\
\hline 2011 & 13463 & 783 & 62 & 5354 & 11665 & 631 & 63 & 5354 & 19441 & 1998 & 312 & 5354 & 14791 & 579 & 16 & 5354 \\
\hline 2012 & 13968 & 850 & 53 & 5833 & 12290 & 732 & 63 & 5833 & 19482 & 2084 & 299 & 5833 & 15254 & 426 & 11 & 5833 \\
\hline 2013 & 14049 & 907 & 56 & 6837 & 12387 & 943 & 91 & 6837 & 20375 & 2333 & 373 & 6837 & 14710 & 193 & 7 & 6837 \\
\hline 2014 & 14802 & 1027 & 67 & 7616 & 12999 & 1033 & 104 & 7616 & 22769 & 2579 & 512 & 7616 & 15057 & 230 & 8 & 7616 \\
\hline 2015 & 15260 & 1173 & 94 & 8064 & 12974 & 1200 & 147 & 8064 & 25094 & 3028 & 555 & 8064 & 15892 & 269 & 10 & 8064 \\
\hline 2016 & 15062 & 1279 & 110 & 7930 & 11924 & 1248 & 147 & 7930 & 26751 & 2958 & 500 & 7930 & 17330 & 457 & 15 & 7930 \\
\hline Overall & 12765 & 758 & 59 & 5461 & 11239 & 655 & 68 & 5098 & 17930 & 2129 & 348 & 8061 & 13954 & 409 & 12 & 4394 \\
\hline
\end{tabular}

SOURCE: Authors' calculations based on IQVIA NSP data, 2004Q4 - 2016 Q3.

NOTES: Revenues collected at the mnf-molform level for each period. 
TABLE 5: MEAN, MEDIAN AND INTERQUARTILE RANGE OF MOLFORM ANNUAL REVENUES BY VINTAGE OVER ALL FORMULATIONS (THOUSANDS)

\begin{tabular}{|c|c|c|c|c|c|c|c|c|c|c|c|c|c|c|c|c|c|c|c|c|}
\hline \multirow[b]{3}{*}{ YEAR } & \multicolumn{20}{|c|}{ VINTAGE } \\
\hline & \multicolumn{4}{|c|}{$<15$ years } & \multicolumn{4}{|c|}{$15-19$ years } & \multicolumn{4}{|c|}{$20-24$ years } & \multicolumn{4}{|c|}{$25-34$ years } & \multicolumn{4}{|c|}{$35+$ years } \\
\hline & Mean & Median & 25-pctile & 75-pctile & Mean & Median & 25-pctile & 75-pctile & Mean & Median & 25-pctile & 75-pctile & Mean & Median & 25-pctile & 75-pctile & Mean & Median & 25-pctile & 75-pctile \\
\hline 2004 & 12704 & 875 & 78 & 5028 & 10934 & 824 & 68 & 5143 & 7375 & 454 & 32 & 3356 & 6866 & 470 & 23 & 3217 & 9998 & 351 & 22 & 3739 \\
\hline 2005 & 13905 & 720 & 82 & 5234 & 10356 & 738 & 71 & 5083 & 7856 & 534 & 40 & 3290 & 7065 & 478 & 32 & 3540 & 10648 & 414 & 28 & 4044 \\
\hline 2006 & 16725 & 591 & 74 & 4555 & 11930 & 790 & 82 & 4944 & 8778 & 585 & 53 & 3643 & 7256 & 489 & 35 & 3443 & 10074 & 424 & 36 & 4132 \\
\hline 2007 & 13182 & 540 & 65 & 3978 & 18282 & 1202 & 126 & 7045 & 8617 & 532 & 56 & 3627 & 8319 & 533 & 43 & 3366 & 10169 & 506 & 37 & 4587 \\
\hline 2008 & 14424 & 545 & 56 & 3821 & 13380 & 1150 & 169 & 5740 & 8147 & 507 & 52 & 3565 & 8582 & 527 & 42 & 3420 & 10346 & 461 & 40 & 4379 \\
\hline 2009 & 12770 & 509 & 60 & 3724 & 17081 & 1148 & 157 & 5252 & 9488 & 775 & 96 & 4348 & 9506 & 576 & 44 & 3537 & 11208 & 533 & 43 & 4534 \\
\hline 2010 & 12982 & 522 & 57 & 3845 & 21137 & 1227 & 115 & 7288 & 10070 & 782 & 86 & 4352 & 9192 & 668 & 54 & 3859 & 13102 & 611 & 41 & 5165 \\
\hline 2011 & 12143 & 461 & 45 & 3503 & 24533 & 1905 & 212 & 9456 & 10534 & 886 & 62 & 5429 & 9771 & 807 & 57 & 4566 & 13632 & 685 & 55 & 5673 \\
\hline 2012 & 13583 & 359 & 19 & 3849 & 20219 & 1810 & 203 & 8909 & 13136 & 1134 & 103 & 6287 & 10928 & 894 & 67 & 4858 & 14068 & 780 & 47 & 6505 \\
\hline 2013 & 11648 & 249 & 14 & 3516 & 17814 & 1825 & 178 & 9678 & 15480 & 1497 & 124 & 8398 & 12034 & 970 & 76 & 6136 & 14728 & 1024 & 57 & 7596 \\
\hline 2014 & 13901 & 272 & 15 & 3880 & 12596 & 1307 & 126 & 9388 & 19856 & 1606 & 128 & 9601 & 13126 & 1141 & 78 & 7391 & 15669 & 1218 & 83 & 8214 \\
\hline 2015 & 15109 & 254 & 15 & 4174 & 11577 & 1509 & 150 & 8526 & 18352 & 1693 & 167 & 8903 & 13767 & 1186 & 99 & 7824 & 16626 & 1454 & 154 & 9108 \\
\hline 2016 & 14318 & 371 & 27 & 4745 & 12334 & 1604 & 149 & 8033 & 17683 & 1665 & 170 & 8275 & 13332 & 1371 & 113 & 7392 & 16395 & 1438 & 137 & 8898 \\
\hline Overall & 13627 & 450 & 39 & 4001 & 15760 & 1292 & 138 & 7382 & 11955 & 854 & 81 & 5470 & 10051 & 716 & 54 & 4582 & 13609 & 801 & 56 & 6265 \\
\hline
\end{tabular}

SOURCE: Authors' calculations based on IQVIA NSP data, 2004Q4 - 2016 Q3.

NOTES: Revenues collected at the mnf-molform level for each period. 


\section{APPENDIX FIGURE 1a Orals}

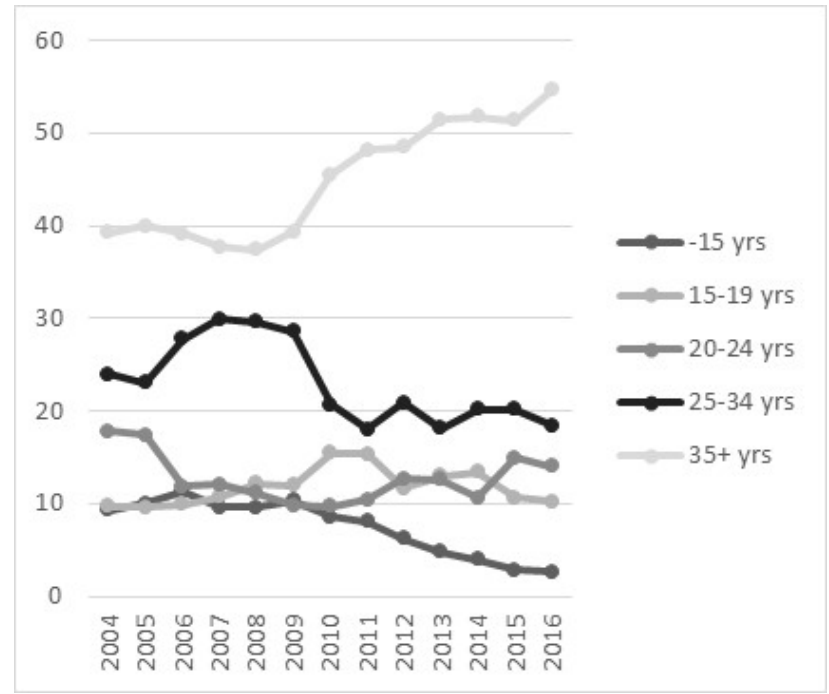

APPENDIX FIGURE $1 \mathrm{~b}$ Injectibles

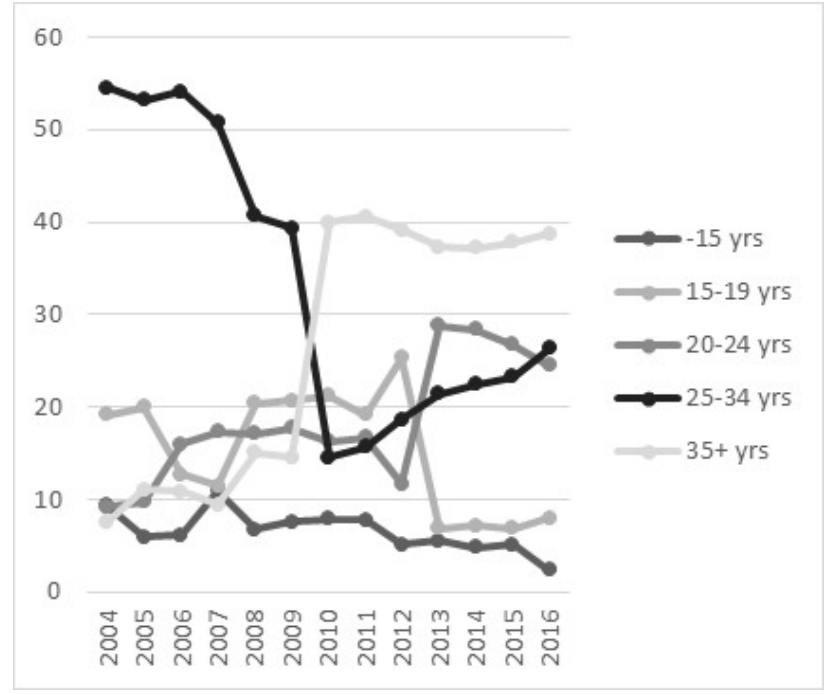

APPENDIX FIGURE 1c Others

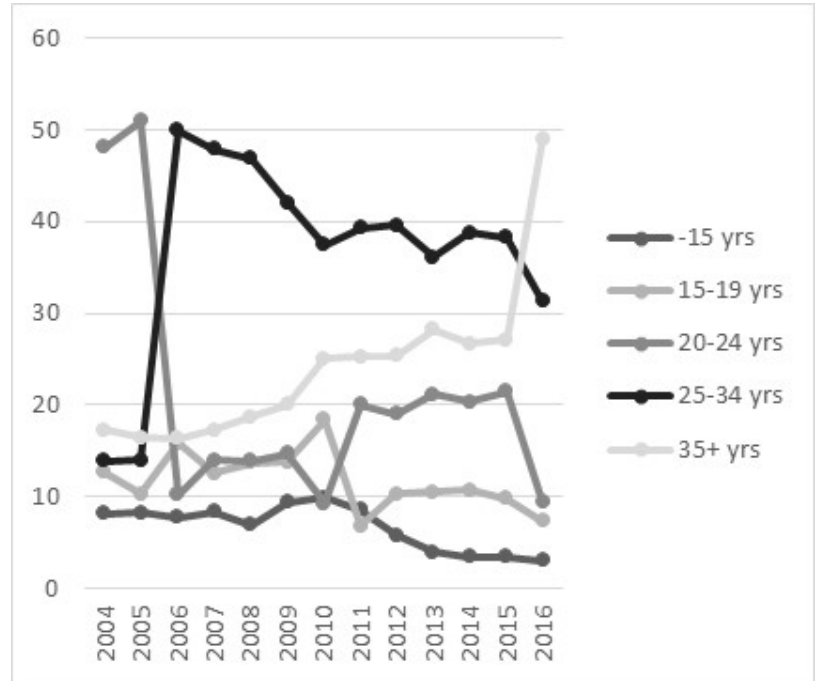

SOURCE: Authors' calculations based on IQVIA NSP data, 2004Q4 - 2016Q3 


\begin{tabular}{|c|c|c|c|c|c|c|c|c|c|c|c|c|c|c|c|c|c|c|c|c|}
\hline \multirow{2}{*}{\multicolumn{5}{|c|}{ APPENDIX TABLE 1a Orals }} & & & & & \multicolumn{4}{|c|}{ VINTAGE } & \multirow{2}{*}{\multicolumn{4}{|c|}{ 25-34 years }} & \multirow{2}{*}{\multicolumn{4}{|c|}{$35+$ years }} \\
\hline & & & & & & $15-19$ & years & & & $20-24$ & years & & & & & & & & & \\
\hline YEAR & Mean & Median & 25-pctile & 75-pctile & Mean & Median & 25-pctile & 75-pctile & Mean & Median & 25-pctile & 75-pctile & Mean & Median & 25-pctile & 75-pctile & Mean & Median & 25-pctile & 75-pctile \\
\hline 2004 & 2.65 & 1.00 & 1.00 & 3.00 & 4.25 & 3.00 & 1.00 & 6.00 & 6.19 & 4.00 & 1.00 & 9.50 & 6.18 & 4.00 & 2.00 & 9.00 & 8.11 & 7.00 & 4.00 & 11.50 \\
\hline 2005 & 2.75 & 1.00 & 1.00 & 3.00 & 4.76 & 3.00 & 1.00 & 7.00 & 6.46 & 4.00 & 1.00 & 10.00 & 6.40 & 4.00 & 2.00 & 10.00 & 8.52 & 7.00 & 4.00 & 12.00 \\
\hline 2006 & 2.92 & 1.00 & 1.00 & 4.00 & 4.66 & 3.00 & 1.00 & 6.00 & 6.13 & 3.50 & 1.00 & 10.00 & 6.44 & 4.00 & 2.00 & 10.00 & 8.15 & 7.00 & 4.00 & 11.50 \\
\hline 2007 & 2.88 & 1.00 & 1.00 & 3.00 & 5.92 & 4.00 & 1.00 & 9.00 & 5.27 & 3.00 & 1.00 & 7.00 & 6.31 & 4.00 & 2.00 & 10.00 & 8.28 & 7.00 & 4.00 & 12.00 \\
\hline 2008 & 2.52 & 1.00 & 1.00 & 2.00 & 6.67 & 4.50 & 2.00 & 10.00 & 6.07 & 4.00 & 1.00 & 9.00 & 6.46 & 4.00 & 2.00 & 10.00 & 8.83 & 7.00 & 4.00 & 13.00 \\
\hline 2009 & 2.38 & 1.00 & 1.00 & 2.00 & 6.76 & 5.00 & 2.00 & 10.00 & 5.68 & 4.00 & 1.00 & 7.00 & 6.42 & 4.00 & 2.00 & 11.00 & 8.92 & 7.00 & 3.00 & 12.00 \\
\hline 2010 & 2.28 & 1.00 & 1.00 & 2.00 & 7.22 & 6.00 & 2.00 & 11.00 & 5.78 & 4.00 & 2.00 & 8.00 & 5.99 & 4.00 & 2.00 & 9.50 & 8.43 & 7.00 & 3.00 & 12.00 \\
\hline 2011 & 2.16 & 1.00 & 1.00 & 2.00 & 7.34 & 5.00 & 2.00 & 11.00 & 5.83 & 4.00 & 1.00 & 8.00 & 5.93 & 4.00 & 2.00 & 9.00 & 8.15 & 7.00 & 3.00 & 12.00 \\
\hline 2012 & 2.14 & 1.00 & 1.00 & 2.00 & 8.11 & 6.00 & 3.00 & 13.00 & 6.76 & 4.00 & 2.00 & 11.00 & 6.09 & 4.00 & 2.00 & 9.00 & 8.09 & 6.00 & 3.00 & 12.00 \\
\hline 2013 & 2.12 & 1.00 & 1.00 & 2.00 & 8.07 & 6.00 & 2.00 & 14.00 & 7.16 & 5.00 & 2.00 & 11.00 & 6.34 & 5.00 & 2.00 & 9.00 & 7.89 & 6.00 & 2.00 & 12.00 \\
\hline 2014 & 2.10 & 1.00 & 1.00 & 2.00 & 7.75 & 6.00 & 2.00 & 13.00 & 7.28 & 5.00 & 2.00 & 11.00 & 6.46 & 5.00 & 2.00 & 9.00 & 7.80 & 6.00 & 2.00 & 12.00 \\
\hline 2015 & 2.02 & 1.00 & 1.00 & 2.00 & 7.21 & 5.50 & 2.00 & 11.00 & 8.86 & 8.00 & 3.00 & 13.00 & 6.56 & 5.00 & 2.00 & 9.00 & 7.91 & 6.00 & 3.00 & 11.00 \\
\hline 2016 & 2.03 & 1.00 & 1.00 & 2.00 & 7.28 & 6.00 & 2.00 & 11.00 & 8.36 & 7.00 & 3.00 & 13.00 & 6.69 & 4.50 & 2.00 & 11.00 & 7.90 & 6.00 & 2.00 & 12.00 \\
\hline Overall & 2.35 & 1.00 & 1.00 & 2.00 & 6.63 & 5.00 & 2.00 & 10.00 & 6.55 & 4.00 & 2.00 & 10.00 & 6.33 & 4.00 & 2.00 & 9.00 & 8.16 & 6.00 & 3.00 & 12.00 \\
\hline
\end{tabular}

APPENDIX TABLE $1 \mathrm{~b}$ Injectibles

VINTAGE

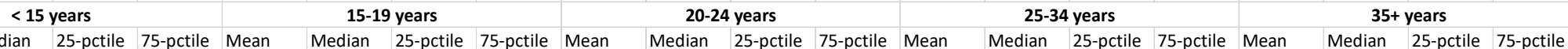

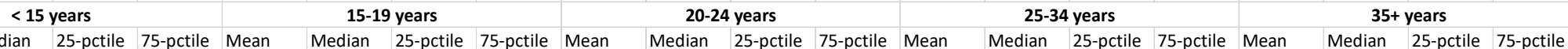

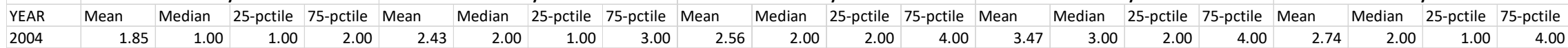
\begin{tabular}{|l|l|l|l|l|l|l|l|l|l|l|l|l|l|r|r|r|r|r|r|r|r|r|r|}
\hline 2004 & 1.85 & 1.00 & 1.00 & 2.00 & 2.43 & 2.00 & 1.00 & 3.00 & 2.56 & 2.00 & 2.00 & 4.00 & 3.47 & 3.00 & 2.00 & 4.00 & 2.74 & 2.00 & 1.00 & 4.00 \\
\hline 2005 & 1.85 & 1.00 & 1.00 & 2.00 & 2.81 & 2.00 & 1.00 & 4.00 & 2.79 & 2.00 & 2.00 & 4.00 & 3.60 & 3.00 & 2.00 & 4.00 & 3.04 & 2.00 & 1.00 & 4.00 \\
\hline
\end{tabular}

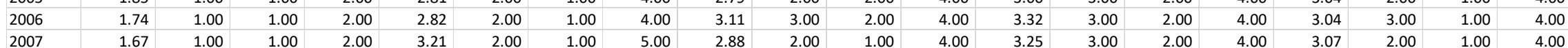

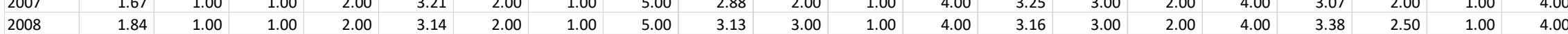

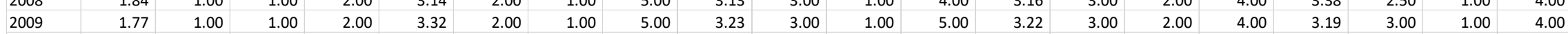
\begin{tabular}{|l|l|l|l|l|l|l|l|l|l|l|l|l|l|l|l|l|l|l|l|l|}
\hline 2010 & 1.70 & 1.00 & 1.00 & 2.00 & 3.02 & 2.00 & 1.00 & 4.50 & 2.91 & 2.00 & 1.00 & 4.00 & 3.22 & 3.00 & 2.00 & 4.00 & 3.55 & 3.00 & 2.00 & 5.00 \\
\hline
\end{tabular}

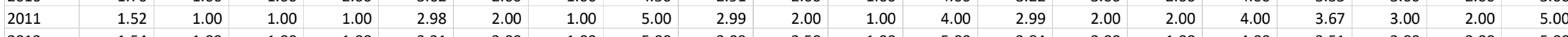

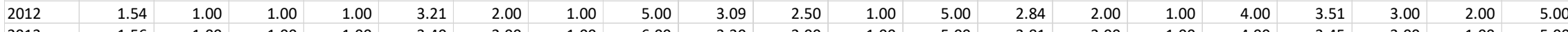

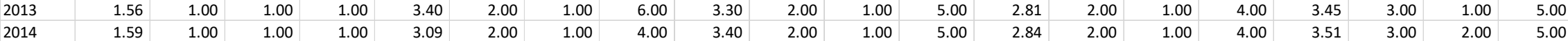
\begin{tabular}{|l|l|l|l|l|l|l|l|l|l|l|l|l|r|r|r|r|r|r|r|r|r|}
\hline 2015 & 1.57 & 1.00 & 1.00 & 1.00 & 3.44 & 2.00 & 1.00 & 5.00 & 2.97 & 1.00 & 1.00 & 4.50 & 2.75 & 2.00 & 1.00 & 4.00 & 3.34 & 2.50 & 1.50 & 4.50 \\
\hline
\end{tabular} \begin{tabular}{|l|l|l|l|l|l|l|l|l|l|l|l|l|r|r|r|r|r|r|r|r|}
\hline 2016 & 1.57 & 1.00 & 1.00 & 1.50 & 2.63 & 1.00 & 1.00 & 4.00 & 3.28 & 2.00 & 1.00 & 5.00 & 2.97 & 2.00 & 1.00 & 4.00 & 3.05 & 2.00 & 1.00 & 4.00 \\
\hline
\end{tabular} $\mid$

APPENDIX TABLE 1c Others

$<15$ years

15-19 years

VINTAGE

20-24 years

25-34 years

$35+$ years

YEAR Mean Median 25-pctile 75-pctile Mean Median 25-pctile 75-pctile Mean Median 25-pctile 75-pctile Mean Median 25-pctile 75-pctile Mean Median 25-pctile 75-pctile \begin{tabular}{|l|l|l|l|l|l|l|l|l|l|l|l|l|r|r|r|r|r|r|r|r|r|}
\hline 2004 & 1.52 & 1.00 & 1.00 & 1.00 & 2.85 & 1.00 & 1.00 & 3.00 & 3.83 & 3.00 & 1.00 & 5.00 & 4.69 & 3.00 & 1.00 & 7.00 & 9.62 & 6.00 & 5.00 & 11.00 \\
\hline
\end{tabular}

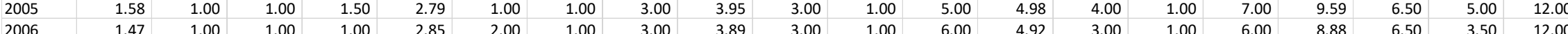

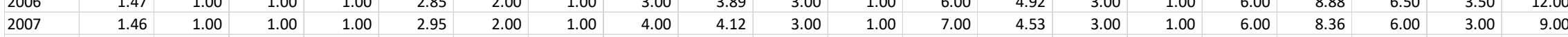

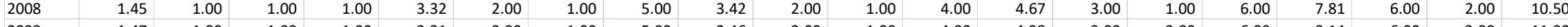

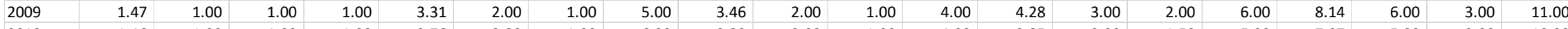

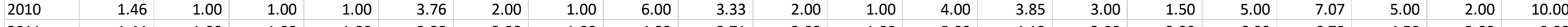

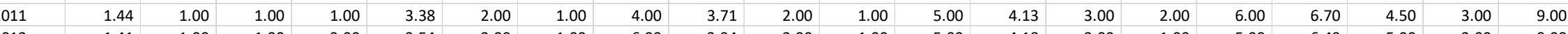

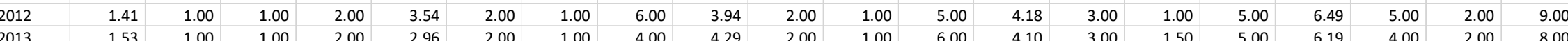

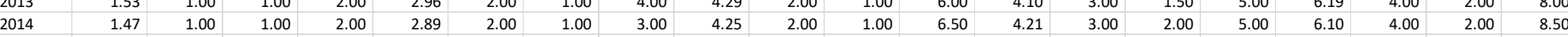
\begin{tabular}{|l|l|l|l|l|l|l|l|l|l|l|l|l|l|l|l|l|l|l|l|l|}
\hline 2015 & 1.50 & 1.00 & 1.00 & 2.00 & 2.88 & 2.00 & 1.00 & 3.00 & 5.09 & 3.00 & 2.00 & 8.00 & 4.04 & 3.00 & 1.00 & 5.00 & 6.24 & 4.00 & 2.00 & 9.00 \\
\hline
\end{tabular} \begin{tabular}{|l|l|l|l|l|l|l|l|l|l|l|r|r|r|r|r|r|r|r|r|r|r|r|}
\hline 2016 & 1.37 & 1.00 & 1.00 & 2.00 & 2.55 & 2.00 & 1.00 & 3.00 & 4.24 & 2.00 & 1.00 & 8.00 & 4.20 & 3.00 & 1.00 & 5.00 & 5.92 & 3.00 & 2.00 & 8.50 \\
\hline
\end{tabular} SOURCE: Authors' calculations based on IQVIA NSP data, 2004Q4 - 2016Q3 